\title{
ON THE USE OF RPAS IN NATIONAL MAPPING - THE EUROSDR POINT OF VIEW
}

\author{
Michael Cramer ${ }^{1}$, Stéphane Bovet ${ }^{2}$, Manfred Gültlinger ${ }^{3}$, Eija Honkavaara ${ }^{4}$, Andy McGill ${ }^{5}$, Martijn Rijsdijk ${ }^{6}$, Mark Tabor $^{7}$ \& \\ Vincent Tournadre ${ }^{8}$ \\ ${ }^{1}$ Institute for Photogrammetry (ifp), University of Stuttgart, Stuttgart, Germany michael.cramer@ifp.uni-stuttgart.de \\ ${ }^{2}$ swisstopo, Wabern, Switzerland, Stephane.Bovet@swisstopo.ch \\ ${ }^{3}$ Landesamt für Geoinformation und Landentwicklung Baden-Württemberg, Stuttgart, Germany, \\ manfred.gueltlinger@vermbw.bwl.de \\ ${ }^{4}$ Finnish Geodetic Institute, Masala, Finland, eija.honkavaara@fgi.fi \\ ${ }^{5}$ Ordnance Survey Ireland, Dublin, andy.mcgill@osi.ie \\ ${ }^{6}$ Dutch Kadaster, Apeldoorn, The Netherlands, martijn.rijsdijk@kadaster.nl \\ ${ }^{7}$ Ordnance Survey Great Britain, Southampton, United Kingdom, Mark.Tabor@ordnancesurvey.co.uk \\ ${ }^{8}$ Institut Géographique National, Paris, France, v.tournadre@ hotmail.fr
}

\section{EuroSDR}

KEY WORDS: RPAS, unmanned airborne platform, national mapping, EuroSDR

\begin{abstract}
:
Following the latest developments in Remotely Piloted Airborne Systems (RPAS) industry and attending some of the most prominent fairs related to the field of geomatics one easily recognizes that it is RPAS, which is strongly pushed into the civilian market. It really is of interest, if official authorities like National Mapping Agencies (NMAs) are starting to implement the RPASs technology within their specific data acquisition processes - to establish alternatives to their traditional manned photogrammetric survey flights. The European Spatial Data Research organization (EuroSDR), representing European NMAs and research organizations of currently 17 European states, is following UAV developments since end of 2004, where an ongoing activity was created, to continuously update their members on the developments in this technology. As systems consolidated, new impetus was given to more deeply explore the potential RPAS for national mapping. Today first national mapping agencies have already used RPAS based data for first experiments in mapping. Several NMAs are discussing on the future role of this technology within their agencies. This report will try to give an overview on the current situation on the use of RPAS in European mapping agencies. Based on the input from some selected NMAs, their expectations on RPAS technology, the fields of use they foresee in their countryspecific surroundings and - exemplarily - first experiences with this type of technology will be presented. Even though the use of RPAS in NMAs is still new, substantial technical and operational benefits become obvious already. With that, the paper will try to give a state-of-the-art report on the current activities and overall acceptance of RPAS technology in European photogrammetric mapping.
\end{abstract}

\section{INTRODUCTION}

The use of Remotely Piloted Airborne Systems (RPAS) is "en vogue" today and RPASs already offer substantial alternatives to traditional manned airborne platforms. This is quite obvious for example from prominent fairs like intergeo 2011 and 2012, where (land-based) mobile mapping systems (MMS), which was one of the main hot issues from the previous years, was strongly replaced by RPAS. Still the question remains, if all this activity is mainly research driven, i.e. mainly undertaken in or with close cooperation of universities and other research centers. It really is of interest if official authorities like national mapping agencies (NMAs) are starting to implement the RPASs technology within their specific data acquisition processes.

The European Spatial Data Research organization (EuroSDR) is following the UAV developments since end of 2004 already. At that time a first project was initiated to make a comprehensive list of unconventional platforms and to document their characteristics and intended applications. The second phase then was expected to deal with first empirical data to document the quality of the data acquired by the RPAS remote sensing instruments and to estimate the cost of using them (compared to traditional platforms). This second phase finally did not commence. One of the main reasons was that the project at that time was too much ahead of its time. Thus the project was changed to an ongoing activity, to at least continuously update the representatives from national bodies, who are members of the EuroSDR, on the recent developments in this technology.

This was the situation until recently when new impetus was given to more deeply explore the potential RPAS for national mapping agencies. Today some first national mapping agencies have already used RPAS based data for first experiments in mapping. Several NMAs are discussing on the future role of this technology within their agencies. To support this, EuroSDR as organization recently started to establish an official link to other organizations like UVS International.

This paper will try to give an overview on the current situation on the use of RPAS in European mapping agencies. Based on the input from some selected NMAs, their expectations on RPAS technology, the fields of use they foresee in their special surroundings and - if already available - their first experiences with this type of technology will be presented. With that, the paper will give a state-of-the-art report on the current activities and overall acceptance of this RPAS technology throughout European mapping.

Section 2 will shortly introduce EuroSDR and how the RPAS technology was followed in EuroSDR activities. The Section 3 will give a short overview on the current situation in 7 countries 
on the (future) use of RPAS in national mapping. Three selected empirical projects or research studies from Germany (Section 4.1), France (Section 4.2) and Great Britain (Section 4.3) are presented before the concluding remarks (Section 5).

\section{EUROSDR}

\subsection{EuroSDR in general}

EuroSDR is seen as a "non-profit organisation linking National Mapping and Cadastral agencies with Research Institutes and Universities for the purpose of applied research in spatial data provision, management and delivery" (EuroSDR 2013a). The origin is in the European Organization for Experimental Photogrammetric Research (OEEPE), founded in 1953 based on international treaty. At its $50^{\text {th }}$ anniversary the OEEPE organisation was restructured. At the same time the name was changed to EuroSDR to also reflect that geospatial world is changing and definitely more than just photogrammetry. As mentioned in the current Rolling Research plan 2011-2014 EuroSDR should be seen as the "European research platform for National Mapping and Cadastre Agencies, Academic Institutes, the Private Sector, Industry and User Groups, on issues related to Research \& Development and implementation of technology with respect to optimising the provision of spatial information in a Geoinformation Infrastructure (GI) context" (EuroSDR 2013b). With that EuroSDR offers a quite unique platform to transfer latest technology from research into practice. This transfer between research and practical applications always is one of the main intentions of EuroSDR and also OEEPE.

\subsection{RPAS related activities in EuroSDR}

Unmanned airborne systems are an issue in the current research plan of EuroSDR. One of the key research topics is "Investigation and monitoring of new sensor systems and platforms, related calibration aspects, including digital aerial and satellite sensors, laser and hyper-spectral scanners, SAR sensors, unmanned aerial vehicles, and mobile mapping systems" (EuroSDR 2013b).

It is interesting to note, that the first EuroSDR initiative dealing with unconventional Earth observation platforms including unmanned airborne systems was already started end of 2004 . This so-called NewPlatforms project was designed to have two phases. The first should deliver a comprehensive list of unconventional platforms to document their characteristics and intended applications, which later was published in EuroSDR official publication No. 56 (Everaerts 2009). The second phase should offer empirical data to demonstrate the quality of the data acquired by their remote sensing instruments and to estimate the cost of using unconventional Earth observation platforms especially in comparison to traditional platforms. This second phase finally did not commence. Obviously at that time RPAS was too far from traditional national mapping applications and not really of interest and relevance to the NMAs. Thus the NewPlatforms project was changed into an ongoing activity, to deliver regular reports to EuroSDR meetings and to also engage with the ISPRS inter-commission working group "UVS for mapping and monitoring applications" (from 2008-now).

End of 2010 the question again arose to explore the potential of a EuroSDR project aimed at transferring knowledge on the potential use of RPASs to NMAs. It was Jurgen Everaerts, who also was in charge of the NewPlatforms project / activity, who at that time stated that "the use of UAS has become common place photogrammetry and remote sensing." In 2011 a round table discussion with all the participating NMAs was organized. It became obvious that RPAS technology is already of concern not only in research but also in potential operational project environments. Some EuroSDR delegates attending the round table also showed first experience in the field of RPAS. From this, the idea was born to report the already available experiences and also individual expectations on the use of UAV technology in European national mapping. This basically was the starting idea for this paper.

In parallel EuroSDR decided to support UAV-g in Zurich, September 2011, and also started contacts with UVS International organization (UVS International 2013). This organization represents manufacturers of unmanned vehicle systems, sub-systems and critical components for UVS and associated equipment, as well as companies supplying services with or for UVS, research organizations and academia with clear European focus. Just recently EuroSDR and UVS International decided to establish a formal Memorandum of Understanding (MoU) to closer link activities of both organisations. UVS International is also interested to bring the NMAs as one stakeholder group using RPAS into his community.

\section{SITUATION OF EUROSDR MEMBERS}

The following exemplarily describes the current country specific situation, experiences, concepts or ideas to use RPAS in national mapping. All this was originated from the round table discussion (see Section 2.2). It is based on input provided by the individual organizations, which already was used to compile a short article in the current RPAS Yearbook 2013, prepared by UVS International (UVS International 2013). It becomes visible, that RPAS is of interest for almost all of the selected NMAs, but only few of them already have accessed real data. Right now, none of the NMAs has already fully integrated RPAS into production lines. Some of the organizations like IGN France and FGI Finland (institute dedicated to research) are also spending significant efforts into the development of their own system components for RPAS use.

\subsection{Finland - Finnish Geodetic Institute (FGI)}

The Finnish Geodetic Institute (FGI) is a research and expert institute that carries out research and development for spatial data infrastructures.

FGI has been following RPAS technology since 2005 and acquired its first multi-rotor RPAS in 2009. Since then, FGI has acquired and built several single and multi-rotor RPAS, like Microdrones MD3-200, Microdrones MD4-1000, Mikrokopter HexaXL, Mikrokopter OktoXL, Align T-Rex 700E, T-Rex 600E, Minicopter Maxi-Joker 3DD. The major objectives in the RPAS research include developing and investigating new sensor instrumentation, developing geometric and radiometric processing methods, including also calibration methods, to study change detection approaches and processes, to investigate phenomenons in nature and to study the feasibility of new systems for various applications. A RPAS platform is a tool for sensor-based research at FGI and allows research to be done in a flexible way: to obtain data from small areas when data is needed.

FGI's interests cover various types of RPAS. The systems owned by FGI are with electric propulsion, having a maximum payload of $1 \mathrm{~kg}$ to $10 \mathrm{~kg}$, and an endurance of $5 \mathrm{~min}$ to $20 \mathrm{~min}$. They are operated with lower than $150 \mathrm{~m}$ flying altitude under visible control, either using autopilots or manually. With these 
systems, it is possible to collect detailed data over up to $0.25 \mathrm{~km}^{2}$ object areas in a single flight. The experiments with fixed-wing RPASs are carried out in co-operation with other research groups or companies; these are suitable for flight campaigns covering larger areas, for instance $1 \mathrm{~km}^{2}$.

Important instrumentation tested on RPAS platforms include consumer-grade light weight cameras, including IR, lightweight laser scanner coupled with GNSS/IMU system and novel spectrometric RPAS cameras. Rigorous radiometric and geometric processing using these systems is the important research objective at the FGI. Currently, FGI is participating the European Union Metrology Research Program (EMRP) to develop SI-traceability of radiometric and geometric RPAS measurements. It is also leading a new European project Advanced_SAR, where RPAS technology is used to calibrate satellite-based canopy height information. The important application oriented studies have included agricultural crops, water quality monitoring, forest change, fluvial studies and documentation of built area.

Current regulations in Finland state that mini RPASs and smaller can be operated within line of sight of operator at lower than $150 \mathrm{~m}$ flying height without any special permission; by allocating the air space it is also possible to use higher altitudes and cover larger areas. The empirical results have proven that the RPAS technology is suitable to produce orthophoto mosaics and 3D surface information with better than $10 \mathrm{~cm}$ accuracy, from low flying altitudes. These aspects make the RPAS technology feasible for various national small-area map updating and cadastral assignments in Finland.

Currently, the National Land Survey of Finland does not see RPAS as an optional technology to perform their task, i.e. to create nationwide datasets. For them, RPAS is laborious technology when large areas need to be covered costeffectively.

\subsection{France - Institut Géographique National (IGN)}

The "Institut National de l'Information Géographique et Forestière (IGN)" is the French mapping and forestry agency. IGN is responsible for the production and distribution of national core geographic information. 1700 people are working in IGN; IGN has also an activity in research (70 people) and teaching (60 people). Research and teaching activities cover all the aspects of geographic information: geodesy, photogrammetry, instrumentation, GIS and cartography.

Until now, IGN data acquisitions with RPAS were all experimental and occurred in teaching or research context. Since 2008, more than 10 RPAS projects have been realized in collaboration with different partners using fixed, and rotary wings, electric and oil engine. All these acquisitions have been processed using the IGN's free open source photogrammetric suite MicMac/Apero. In 2012 IGN has acquired its first own RPAS (hexacopter).

The IGN Laboratoire of Optronique Electronique and Micro Informatique (LOEMI, Saint Mandé) is developing a camera which is especially designed for photogrammetric applications with RPAS: around 200g, 10 images per second, electronic shutter. One added value of this camera will be to allow stereoscopic acquisition from low altitudes $(50 \mathrm{~m})$ using electric propulsion RPAS. In addition, two $\mathrm{PhD}$ research projects have been started recently: The first one is dealing with the metrological survey of dykes by RPAS, the second work on canopy height estimation using RPAS. The dyke survey project will be described in more detail in Section 4.2.

Due to the current French law and state of the art, RPAS are unlikely to be used to acquire data for national cartographic purposes before years. However, the development of an industrial activity using RPAS for metrological survey is in the strategy of IGN.

\subsection{Switzerland - swisstopo}

The Federal Office of Topography (swisstopo) is the center of competence for geographical reference data of the Swiss Confederation. As such, swisstopo handles tasks such as the description, representation and archiving of geographic spatial data like national maps, satellite images, orthophotos, elevation and landscape models. swisstopo provides measurements of Switzerland, ascertains and documents changes in the landscape (geological, geodesic and topographical) and produces maps of Switzerland.

For some spatial data and geographic information, field work for local mapping tasks remains a requirement to complete the existing databases. Regarding mapping purposes, RPAS have attained a significant maturity during the last few years. A wide number of small, medium as well as large RPAS's are operating under different conditions, completing or replacing some standard sensor platforms. swisstopo started evaluating the use of mini and small RPAS as platforms for local mapping purposes. The use of RPAS in national mapping is stimulated by the favorable situation in Switzerland, where small RPAS can be operated below 300m flying height within line-of-sight conditions without need for individual permission to fly.

In a first step, the potential uses of the RPAS are going to be defined, regarding the systems capacities. An open issue is for example the decision to use one single or many systems for rapid mapping and local mapping purposes. In a second step, a limited number of test systems should be operated over typical topographic areas to evaluate the operating and handling aspects. Can anyone use a RPAS as easily as a GNSS receiver or a field book, or will this use be restricted to few specialists? In a third step, existing workflows should be updated for the RPAS imagery.

\subsection{Ireland - Ordnance Survey Ireland (OSi)}

Ordnance Survey Ireland (OSi) is the National Mapping Agency and has been mapping Ireland since 1824. OSi data is a national asset and resource delivering value for money to the State, private enterprise and the citizens of this state. It has a mandate to create and maintain the definitive national mapping and related geographic records of the State, including the maintenance of the national grid and the national geodetic and height frameworks and to link these to international systems. In creating and maintaining the various definitive national datasets for Ireland, OSi uses airborne imagery captured at resolutions between $25 \mathrm{~cm}$ and $1.0 \mathrm{~m}$ using large format digital aerial camera systems. In recent years the expectation and demand to provide higher accuracies is ever increasing. However as a National Mapping Agency tasked with the mapping of the entire state a balance of cost $\mathrm{v} / \mathrm{s}$ high end specialist products must be achieved. With technology continuing to advance at an exponential pace within all the various imaging platforms, the introduction of RPAS is not surprising.

While OSi have not yet endorsed this technology we have been actively monitoring and collaborating with private users on the capabilities and the regulatory requirements to operate such systems.

Our initial findings is that while the achievable image resolution from these systems and consequently the accuracies of final products are definitely suitable for many smaller project 
situations it is not a technology that could be considered from a national image collection perspective at this time. As an example the use of RPAS in positioning of high and low watermarks could work very well as you can only map short sections of coastline in a given timeframe. With weather conditions in Ireland and low cloud bases RPAS might offer a good solution. However there is some additional project based activities, that OSi as the national mapping agency could justify utilising this technology but current operational regulation in Ireland would prevent the use of this technology particularly in urban areas: for example for the accurate positioning of boundaries where access might not be possible. There is also potential in utilising this technology for city modeling and updating of 3D data.

As RPAS based mapping is a relatively new technology and development is at an early stage OSi would be anxious that deployment regulation in the future would facilitate a wider range of uses.

\subsection{United Kingdom - Ordnance Survey Great Britain}

Ordnance Survey (OS) is the national Mapping Agency of Great Britain. It has traditionally utilised aerial imagery to update OS MasterMap, the OS MasterMap Imagery Layer, plus a new Digital Terrain Model product.

The normal mechanism to deliver this imagery is to use specifically designed large format aerial digital cameras from piloted fixed wing aircraft. Ordnance Survey currently uses two digital cameras capable of producing imagery at very high resolution (equivalent to 196 megapixel cameras). However OS is aware of the ever increasing interest in the utilisation of RPAS. In order to understand the potential operational issues and efficiencies, Ordnance Survey purchased a UAV in 2011 (Sensefly Swinglet system). The system allows the operator to flight plan an aerial target, feed in the information automatically to the RPAS, and take off within five minutes. It has the additional facility of 'Drag and drop' of live flight plan modifications whilst the RPAS is in the air. The UAV is battery powered, utilises an off-the-shelf 12 megapixel digital camera and can operate for up to 30 minutes at a time. It is $500 \mathrm{~g}$ in weight, with an $80 \mathrm{~cm}$ wingspan.

Ordnance Survey is currently determining the potential benefits either in the way of efficiencies or by creating new products that could benefit our customers. First more research based projects have already been done. Some more details are given in Section 4.3 .

There is no doubt that RPAS are a cost efficient way of acquiring imagery, with the environmental and cost savings obvious over traditional airborne aircraft. RPAS imagery can be utilised for the following potential purposes:

- $\quad$ Mapping for emergencies - (for example, creating imagery to determine extent of flooding).

- Mapping of coastal erosion - (where conditions make it difficult to operate by foot).

- Updating Digital Terrain Models in known areas of change.

- Large scale topographic mapping update in small areas.

Current research continues to look at how to overcome operational limitations including the fact that many RPAS cannot be flown in wind conditions over $25 \mathrm{~km} / \mathrm{h}$, plus restrictions imposed by the Civil Aviation Authority. However, the UAV could provide Ordnance Survey with a low cost alternative imagery creation tool that allows us to deliver change quicker to our customers.
OS continues to track the increasing amount of new technical options now available, including platforms with stabilised mounts, with Lidar, and systems that are more tolerant of wind conditions. Freely available post processing of imagery now challenges the traditional approach to photogrammetry: software is now capable of producing high accuracy DTM's and Mosaic's with the use of automatic pixel matching techniques.

\subsection{Germany - Landesamt für Geoinformation und Landentwicklung Baden-Württemberg (LGL BW)}

The "Landesamt für Geoinformation und Landentwicklung Baden Württemberg (LGL BW)" is reponsible for the mapping, cadaster, land consolidation and land management and the geodata infrastructure of the state of Baden-Württemberg, located in the southwest of Germany as one of the 16 federal states. The LGL BW is the agency to provide the state wide geo-basis data from national mapping and cadaster. This includes the products of the official topographic information system (ATKIS) with digital orthophotos, the digital 3D models, the digital landscape model and the official topographic maps.

Cyclic airborne image flights are performed using traditional manned aircrafts and photogrammetric large format digital cameras to regularly update this geodata. The flights are done during summer time, covering the whole state of BadenWürttemberg every three years, with $20 \mathrm{~cm}$ ground sampling distances GSD. In addition, smaller area flights with higher resolutions below $10 \mathrm{~cm}$ are carried out in spring time to support the planning in land consolidation processes or for updating of 3D and digital landscape models.

The LGL BW was the German national mapping agency, which firstly evaluates the potential of RPAS for national mapping purposes! This pilot test was done in cooperation with the Institute for Photogrammetry (ifp) at the University of Stuttgart, thus linking agency and research, which in the end was proven as a very fruitful cooperation. The application behind this test was to get high resolution orthophotos and 3D models for a land consolidation site, with requested geometric accuracy better than $10 \mathrm{~cm}$. The empirical tests were done using two different fixed wing RPAS of mini category, standard of-theshelf 12Mpix cameras were used for image acquisition.

The results of this first study were very promising and are presented in more detail in Section 4.1. RPAS based photogrammetric data acquisition is seen as a true alternative, especially for application oriented flights in small areas. It is definitely a cost-efficient option and ready-to-go for practical, operational use.

LGL BW will continue such cooperation with agencies, private companies and the ifp. In summer 2013 further tests using multicopter RPAS will be made. Especially for those applications, where users need highest actuality within their geo-basis data, LGL BW sees great potential for the use of RPAS. RPAS can also be used for documentation purposes or small area planning. But it should also be mentioned here, that the current policy to flexibly get permissions to fly at least currently limits the commercial use of RPAS.

\subsection{The Netherlands - Dutch Kadaster}

Netherlands' Cadastre, Land Registry and Mapping Agency Kadaster in short, collects and registers administrative and spatial data on property and the rights involved. This also goes for ships, aircraft and telecom networks. Doing so, Kadaster protects legal certainty and also is responsible for national mapping and maintenance of the national reference coordinate 
system. Furthermore, Kadaster serves as advisory body for landuse issues and national spatial data infrastructures.

During the cadastral verification of borders, many customers are not able to make their attendance. New appointments have to be made in order to do the verification process again, which increases costs. In order to prevent this, parts of the cadastral process need to be improved. Thus Kadaster starts experiments with high resolution pictures taken from RPAS. Using these photos, it is unnecessary for customers to physically attend to the cadastral verification. At the beginning of 2012 Kadaster started an experiment using RPAS. Kadaster had no previous experience. A cooperation was started with the KLPD (National Police), the National Space and Aerial Association (NLR) and a commercial organisation Orbit GIS. All experiments provide answers to the research question how useful a Remotely Piloted Aerial System is in the juridical verification process of cadastral ownership at Kadaster. The main conclusions can be seen as follows, further information on the tests is given in van Hingsberg et al. (2013).

- An RPAS is a useful system for making high resolution pictures above high density populated living areas;

- High resolution pictures which are generated into orthophotos made by an RPAS are at least as good as conventional terrestrial surveying methods. Experiment showed geometrical accuracies above living areas with a maximum of $3 \mathrm{~cm}$. It makes orthophotos useful for using them in the cadastral verification of ownership.

- High resolution pictures/ orthophotos could be used also for other cadastral applications. Examples are areas which are poorly accessible or intensive infrastructural works.

\section{RPAS TESTS IN NATIONAL MAPPING}

\subsection{RPAS for land consolidation}

In year 2012 the ifp started a project together with the Landesamt für Geoinformation und Landentwicklung BadenWürttemberg (LGL), the national mapping agency (NMA) of Baden-Württemberg. Within this project the performance of UAS for the mapping of small areas was evaluated. The LGL here served as a pilot user for all the other national mapping agencies in the federal states of Germany. The goal was to get the 3D surface model and orthophoto of a (quite steep) vineyard area, located at the Neckar River, around $25 \mathrm{~km}$ north of Stuttgart. It is the so-called "Hessigheimer Felsengärten" that has been flown, as the LGL did a land consolidation (Flurbereinigung) in that area recently. This is one of the aspired fields of applications where RPAS might be used by NMAs in future. Such projects are quite limited in size often and request for frequently updated airborne data just to illustrate the land owners how parcels have been changed and what the current status of the whole process is.

In cooperation with the Institute of Flight Mechanics and Control (iFR) at University of Stuttgart, flights were done in that area. The LGL requested to have 3D point clouds, with GSD $<10 \mathrm{~cm}$ and orthophotos with the same GSD. In order to guarantee accuracy better than one pixel (i.e. $10 \mathrm{~cm}$ ) the images were taken with a mean nominal GSD around $6 \mathrm{~cm}$. The overall size of the area was $1000 \times 400 \mathrm{~m}^{2}$.

The images were taken by consumer cameras, two different systems have been tested. A Canon Ixus 100 and a Ricoh GXR Mount A12 combined with a Zeiss Biogon 21 mm lens.

It is interesting to see, that when using the Canon and Ricoh/Zeiss images in automatic aerial triangulation (AAT) quality differences in geometric resolution as shown from previous resolution tests are hardly visible, at least, when the final internal and absolute accuracy is investigated. The Table 1 compares the results from the ATs for the Canon and Ricoh/Zeiss flights. In all cases 22 ground control points were used. The absolute accuracy is obtained from 11 check points.

\begin{tabular}{|l|c|c|c|c|}
\hline Camera & $\begin{array}{c}\sigma 0 \\
{[\mathrm{pix}]}\end{array}$ & \multicolumn{3}{|c|}{ RMS from Check Points [m] } \\
\cline { 3 - 5 } & 0.7 & 0.050 & 0.037 & 0.095 \\
\hline $\begin{array}{l}\text { Canon } \\
\text { SfM Points }\end{array}$ & 0.3 & 0.030 & 0.023 & 0.050 \\
\hline $\begin{array}{l}\text { Canon } \\
\text { Match-AAT }\end{array}$ & 0.3 & North & Vertical \\
\hline $\begin{array}{l}\text { Ricoh/Zeiss } \\
\text { SfM Points }\end{array}$ & 0.7 & 0.031 & 0.037 & 0.058 \\
\hline $\begin{array}{l}\text { Ricoh/Zeiss } \\
\text { AAT }\end{array}$ & 0.3 & 0.029 & 0.024 & 0.043 \\
\hline
\end{tabular}

As one can see, it is two different versions shown for each of the two cameras. The first one refers to the adjustment based on the SIFT tie points from the Structure-from-Motion (SfM) approach. This SfM was applied before the bundle adjustment in order to have good approximate values for the exterior orientation of each of the images. The SIFT point matching is known from computer vision and allows for a very dense and robust matching between arbitrarily oriented images. As one can see, the AT using SIFT points is in the range of 1 pixel for both cameras. This accuracy is improved significantly when the SIFT points are exchanged by tie points from least-squares image matching. This is the standard approach implemented in photogrammetric software like the Trimble/inpho Match-AT used here. The quality of homologous points from least-squares matching is much better than from SIFT, which directly influences the internal and external accuracy in object space also. The increase in accuracy is clearly visible, if one looks for the RMS values from check point analyses. In both cases the absolute accuracy is well below $1 / 2$ pix (GSD) in horizontal and well below 1 pix (GSD) in vertical component.

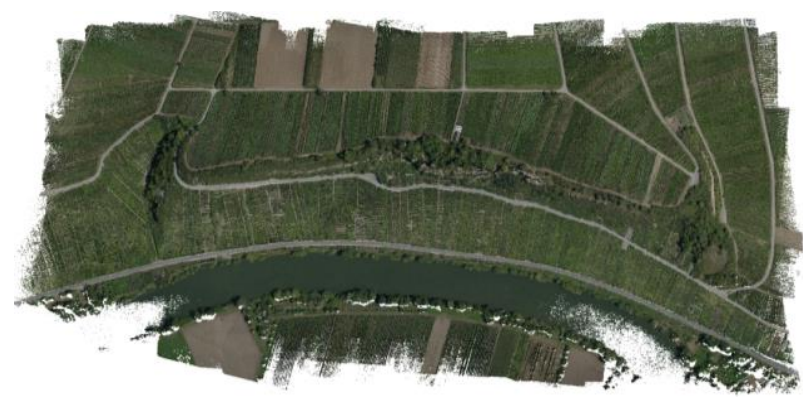

Figure 1: DSM from dense matching.

After AT the exterior orientation of each image is available which is pre-requirement for the generation of 3D point clouds. The determination of dense point clouds is based on the semiglobal matching algorithm which was modified and implemented in the ifp SUrface REconstruction (SURE) software package. With that very dense point clouds are derived. The result, the 3D surface model for the whole Hessigheim project area can be seen in Figure 1.

From technical point of view the project was very successful. All the products according to the requests from the LGL could be derived. The only problem is the effort, which is needed to get the permission to fly the UAS, even in this quite rural area at least for the time when permission was asked. Further details can be seen from Cramer et al. (2013) and Haala et al. (2013). 


\subsection{RPAS for dyke monitoring at Rhône River}

The IGN France has launched a partnership with the CNR (Compagnie Nationale du Rhône) which is a concessionary of the Rhône River and producer of hydraulic energy. A thesis has been started intending to explore the utility of low-altitude RPAS in geomatics and monitoring.

With such high resolved imagery 3D models with up to centimeter accuracy should be possible, which is especially demanding for the vertical component.

While monitoring dykes, changes in height are the most meaningful. Traditional (terrestrial) techniques are very accurate (sub-centimeter), but they end up in a few measures, which only give a rough idea of the evolution. It is now interesting to check, if height data derived from RPAS imagery will be able to compete with traditional methods, in terms of accuracy, quick response times and under financial aspects also. Repeating flights taken at different epochs might be used to monitor small height changes or can even be used to monitor disasters like dyke breaks in flood scenarios.

One of the test sites is the La Pallière's dyke located on the river Rhône near to Belley. This site is monitored by the survey team who set up a network of topographic references. They regularly measure the dyke's surface by leveling, resulting in height differences every $50 \mathrm{~m}$, which yields in about 23 measures for $1100 \mathrm{~m}$ of dyke.

Within the RPAS empirical test, now this $1100 \mathrm{~m}$ should be $3 \mathrm{D}$ reconstructed from airborne images. As the leveling network is not visible from the air 50 new markers were rigidly fixed on the ground, like it is done by land surveyors do to permanently mark parcel boarders. These ground reference points (GCP) have been surveyed with a RTK GPS for X and Y, and with a Leica DNA03 level for $\mathrm{Z}$ to have highest accuracy in the $\mathrm{Z}$-axis. The dyke RPAS survey was done using a hexacopter (Mikrocopter GmbH) equipped with a Sony RX1. This camera has recently been acquired by IGN for aerial photogrammetry purposes. It has a $35 \mathrm{~mm}$ fixed lens with a very good full frame sensor, it is light $(482 \mathrm{~g})$ and it has a global shutter. Indeed, using cameras equipped with a rolling shutter on a mobile platform can lead to aberrations (the upper pixels being recorded before the lower ones).

Flying at a 50 meters altitude, 215 pictures have been taken in 7 strips. Each strip has a 300 meters length; the strips are flown parallel with 12 meters gap, the seventh strip has a U shape as shown in Figure 2.

In order to reduce potential vibrations which may propagate into image blur, a piece of foam and some elastic strap have been helpful (Figure 3 ). Although the set does not look very convincing, it was perfectly fine to overcome any vibrations.

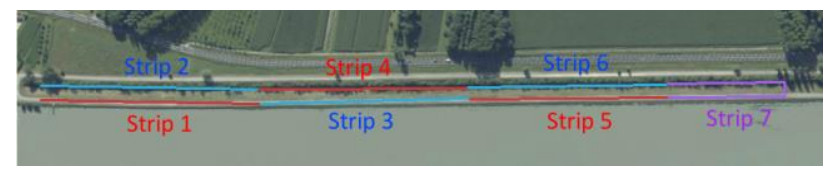

Figure 2: Dyke survey flight plan.

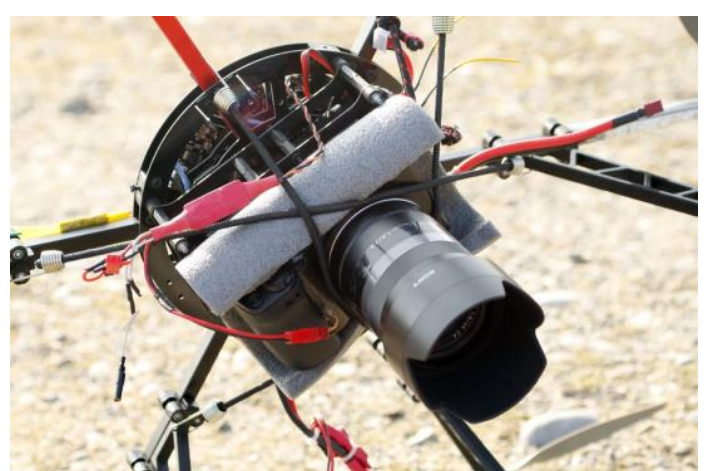

Figure 3: Sony RX1 in hexacopter pod with dampers.

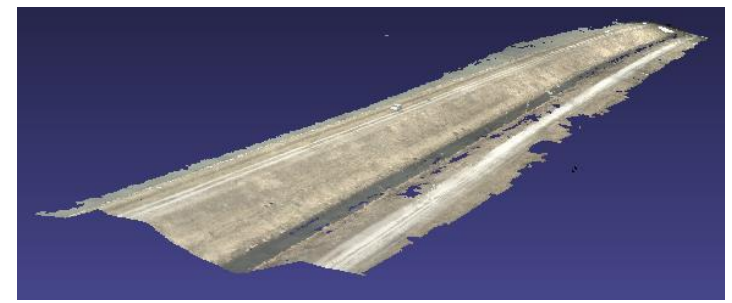

Figure 4: 3D point cloud of the dyke.

The data processing was done using the IGN open-source photogrammetric tools MicMac / Aperol. When using the 50 GCPs to generation a 3D model (Figure 4) the following RMS values around a vew centimeters were derived: $\mathrm{RMS}_{X}=9 \mathrm{~mm}$, $\mathrm{RMS}_{\mathrm{Y}}=10 \mathrm{~mm}, \mathrm{RMS}_{\mathrm{Z}}=26 \mathrm{~mm}$. Although this might seem to be sufficient for many applications, the use of $50 \mathrm{GCP}$ is not very practical as it needs lots of effort and is costly also. Thus in future we will try to reduce the number of control points but remaining the centimetre accuracy.

Another problem to be examined in more details is the obvious bending effect which is present in the photogrammetric block. The following Figure 5 gives shows the interpolated height differences on the dyke reference profile covering the whole $1100 \mathrm{~m}$ dyke. It is the 23 reference points, $50 \mathrm{~m}$ difference each as already mentioned before. As the CNR points could not clearly be seen in the images itself, their height was interpolated from their given position from the DTM derived from matching.

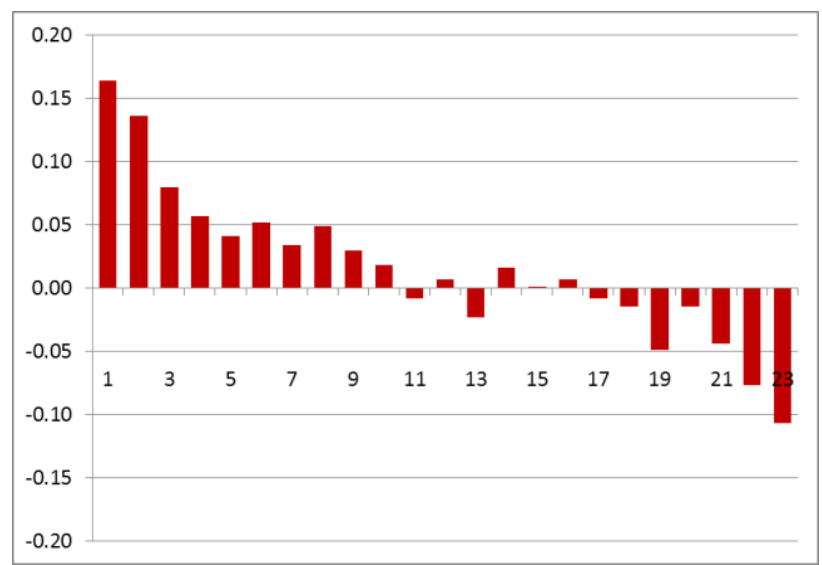

Figure 5: Vertical accuracy [m] from levelling reference points.

The originally aspired centimeter vertical accuracy was not yet reached, which is due to a bending in the block, as known from classical photogrammetry also. There is a general tendency for the derived surface model to bend in its border areas. Nevertheless, this result is encouraging and it will be examined to solve this bending effect. 


\subsection{Research experiences of Ordnance Survey Great Britain to date}

As OS is currently going through the certification process in order to gain more freedom as to where the RPAS can be operated, we have limited the majority of our testing to capturing imagery over our headquarters in Southampton, England. To test the potential of using the RPAS to capture imagery for an urgent requirement (i.e. disaster management) and create a mosaic, we used the extent of our headquarters as an example and worked out how quickly we could operate and create a cheap mosaic.

On our chosen day the wind conditions were conducive to flying the RPAS, so in the space of 20 minutes we flight planned the extent of our site (approximately $100 \mathrm{~m}^{2}$ ), and managed to capture and download 64 images within a further half an hour. We then chose some freely available pixel matching software and "threw" the imagery at the software to see how if would work. Initially results looked acceptable, but anyone with a trained eye could see the areas where the software struggled to match the imagery properly. The figures below show one original sample image (Figure 6) and the obtained mosaic from neighboring images (Figure 7). However, if you want imagery quickly and are not too concerned about the overall quality, the RPAS certainly provides that.
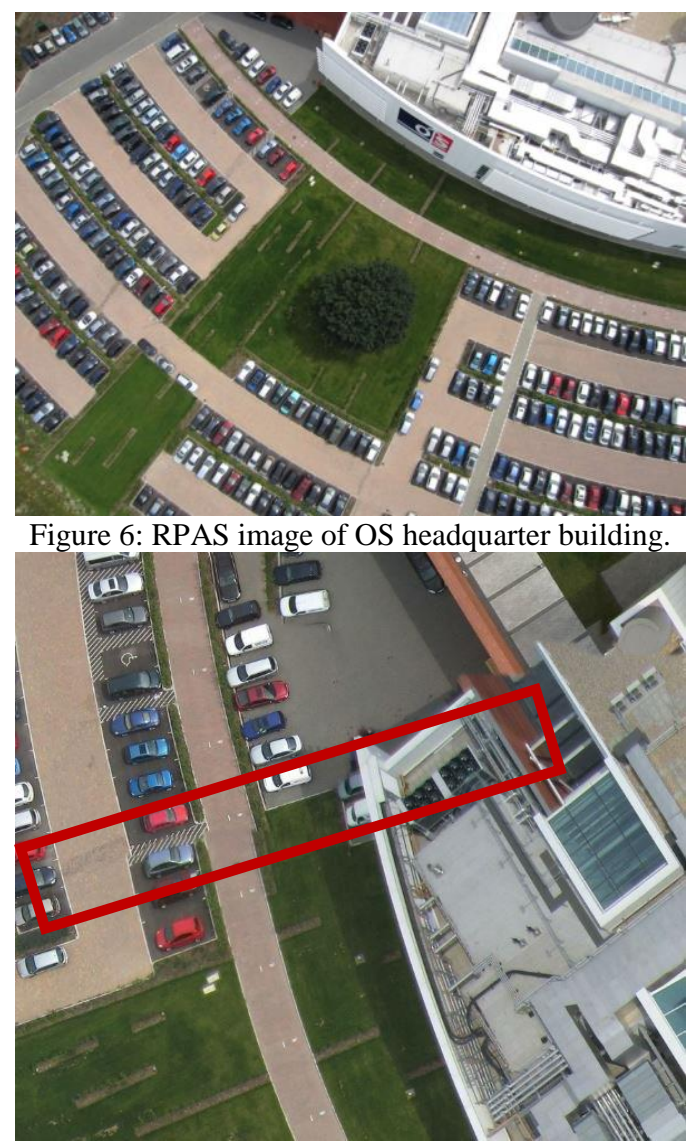

Figure 7: Fast mapping ortho mosaic.

As a lesson learnt exercise it is recognized that in future it should be flown with $80 \%$ overlap, and also cross fly the target with different flight plans that are at 90 degrees to each other. This provides two benefits:

- If the UAV receives a gust of wind that coincides with an image being exposed, the image becomes blurred. The additional imagery captured would mean that we could delete it without losing coverage.

- As long as the free software can handle the increased volume of imagery, it supplies more points for the automatic pixel matching to take place.

\section{SUMMARY}

This paper tried to give a state of the art overview on the use of RPAS in the national mapping sector. As it was shown, almost all of the NMAs participating in this paper are aware of the potential of RPAS. They all are following the most recent developments and are working on a possible integration of RPAS data in their production lines. It is quite obvious, that RPAS will definitely not replace traditional airborne data acquisition with high end, large format cameras or LiDAR sensors. Still, RPAS will be advantageous for those applications where only local areas are of interest. Many of the NMAs not only are interested in nation-wide coverage, but also are involved local application like cadastral applications, land management / land consolidation or disaster monitoring. It is important to note, that - mainly due to the much lower flying heights - RPAS based products are fully comparable to the standard data from manned photo flights. This is impressive as most of the sensors are not especially designed for photogrammetric purposes. Using latest technology for example for automatic image orientation, the derived products are very promising. It will be interesting to see, how fast RPAS will be used as regular working tool in NMAs especially when flight regulations are harmonized throughout Europe.

\section{REFERENCES}

Cramer, M., Haala, N., Rothermel, M., Leinss, B., \& Fritsch, D. (2013): UAV-gestützte Datenerfassung für Anwendungen der Landesvermessung - das Hessigheim-Projekt, in Tagungsband 33. DGPF-Jahrestagung, 3-Ländertagung Freiburg, 27. Februar1. März 2013, pp. 450-469.

Everaerts, J. (2009): NEWPLATFORMS - Unconventional Platforms (Unmanned Aircraft Systems) for Remote Sensing, 102 pages. Frankfurt a.M. 2009, in EuroSDR official publication No 56, online available at http://bono.hostireland.com/ eurosdr/publications/56.pdf, last access May 8, 2013.

Haala, N., Cramer, M. \& Rothermel, M. (2013): Quality of 3D point clouds from highly overlapping UAV imagery, this proceedings, UAV-g 2013 conference, Rostock, September 2013.

van Hingsberg, W., Rijsdijk, M. \& Witteveen, W. (2013): UAS for cadastral applications, in GIM International 27(3), March 2013, pp. 20-25, online available at http://www.giminternational.com/issues/articles/id1968-

UASs_for_Cadastral_Applications.html, last access May 8, 2013.

\section{References from Internet}

EuroSDR (2013a): http://eurosdr.net/start/ , last access May 8, 2013.

EuroSDR (2013b): EuroSDR Rolling Research Plan 20112014, http://www.eurosdr.net/rrp/eurosdr_research_plan_20112014.pdf, last access May 8, 2013

UVS International (2013): http://www.uvs-info.com/, last access May 8, 2013. 